\title{
Caracterização parcial e utilização da fitase extraída de sementes germinadas de girassol
}

\author{
Juliana da Silva Agostini(1) e Elza Iouko Ida(1)
}

(1)Universidade Estadual de Londrina, Centro de Ciências Agrárias, Dep. de Tecnologia de Alimentos e Medicamentos, Caixa Postal 6001, CEP 86051-970 Londrina, PR. E-mail: elida@uel.br

\begin{abstract}
Resumo - O objetivo deste trabalho foi ativar, extrair e caracterizar parcialmente a fitase em sementes germinadas de girassol (Helianthus annuus L.), híbrido M734, e avaliar o efeito da fitase no farelo de girassol. Sementes foram colocadas para germinar por oito dias em câmara a $25^{\circ} \mathrm{C}$. A fitase foi extraída com $\mathrm{CaCl}_{2} 2 \%$, depois do quinto dia de germinação, e fracionada com $\left(\mathrm{NH}_{4}\right)_{2} \mathrm{SO}_{4}$ até $80 \%$ de saturação. O extrato bruto foi caracterizado parcialmente e aplicado em farelo de girassol desengordurado para avaliar a hidrólise do fitato. Com a germinação, houve aumento na atividade da fitase e redução no teor de fitato. A maior atividade da fitase foi observada do quinto ao oitavo dia de germinação. A fitase das sementes germinadas aos cinco dias apresentou atividade ótima em $\mathrm{pH}$ de 5,2 e temperatura de $55^{\circ} \mathrm{C}$. A enzima se manteve estável, quando pré-aquecida por 10 minutos a $50^{\circ} \mathrm{C}$, com $\mathrm{V}_{\text {máx }}$ de $1,87 \mathrm{U} \mathrm{g}^{-1}$ de amostra e $\mathrm{K}_{\mathrm{m}}$ de $0,29 \mathrm{mM}$, indicando alta especificidade pelo fitato. Quando aplicada no farelo de girassol desengordurado, depois de oito horas de incubação, a fitase hidrolisou 92\% do fitato. A germinação de sementes de girassol estimula a atividade da fitase, o que facilita sua extração para a produção de alimentos livres de fitatos.
\end{abstract}

Termos para indexação: Helianthus annuus, girassol híbrido, hidrólise de fitato.

\section{Partially characterization and application of phytase extracted from germinated sunflower seeds}

\begin{abstract}
The objective of this work was to activate, extract and partially characterize the phytase in hybrid sunflower M734 (Hellianthus annuus). The enzyme was extracted from seeds germinated for eight days, with $\mathrm{CaCl}_{2} 2 \%$, fractionated with $\left(\mathrm{NH}_{4}\right)_{2} \mathrm{SO}_{4}$ up to $80 \%$ saturation. The obtained crude extract was partially characterized and applied over defatted sunflower flour in order to evaluate the phytate hydrolysis. In germination, there was an increase in the phytase activity and a reduction of phytate content. The highest enzyme activity was observed from the $5^{\text {th }}$ to the $8^{\text {th }}$ day of germination. The phytase extracted from sunflower seeds at the $5^{\text {th }}$ day of germination presented optimum activity at $\mathrm{pH} 5.2$ and temperature at $55^{\circ} \mathrm{C}$. The phytase was heat stable at $50^{\circ} \mathrm{C}$ for 10 minutes, and presented $V_{\max }$ of $1.87 \mathrm{U} \mathrm{g}^{-1}$ of substract and $\mathrm{K}_{\mathrm{m}}$ of $0.29 \mathrm{mM}$, indicating high specificity to phytate. When applied over defatted sunflower flour, after eight hours of incubation the phytase hydrolyzed $92 \%$ of phytate. Sunflower seeds germination stimulates phytase activity, making easy the extraction process, in the production of phytate-free feed products.
\end{abstract}

Index terms: Helianthus annuus, sunflower hibrid, phytate hydrolysis.

\section{Introdução}

As fosfatases são enzimas amplamente distribuídas na natureza que hidrolisam ésteres fosfatos. A fitase, ou mioinositol-hexafosfato fosfohidrolase, é uma fosfatase fitatoespecífica que catalisa a hidrólise do ácido fítico, ou mioinositol hexafosfato, formando inositol e fosfatos. O ácido fítico é a principal forma de armazenamento de P em se- mentes e pólen (Reddy et al., 1982). Em virtude da habilidade de formar complexos insolúveis com importantes minerais como Ca, Zn e Mg e também com proteínas, o ácido fítico é considerado um constituinte antinutricional, que reduz a biodisponibilidade desses minerais (Maga, 1982). Assim, o uso da fitase seria uma alternativa para aumentar o valor nutricional de muitos alimentos vegetais (Segueilha et al., 1992). 
A fitase foi uma das primeiras enzimas descritas com capacidade de liberar o fosfato inorgânico a partir de fosfato orgânico, ou seja, hidrolisar o ácido fítico em inositol e ácido fosfórico. A distribuição de fitase é ampla em vegetais, tecidos animais e em numerosos tipos de microrganismos (Maga, 1982; Reddy et al., 1982). Segundo Houde et al. (1990), a função fisiológica da fitase em sementes provavelmente está relacionada com a liberação do fósforo inorgânico a partir do fitato, e a maior proporção do fósforo inorgânico hidrolisado é incorporada aos ácidos nucléicos. Além disso, esses autores mencionam que a fitase é responsável pela degradação do fitato e que pode estar relacionada a várias reações celulares com liberação de energia, com relevante função na germinação de sementes, e que o aumento na atividade dessa enzima ocasiona decréscimo no teor de fitatos.

Animais monogástricos, como aves, suínos e o próprio homem, ao consumirem cereais que contêm fosfato na forma de fósforo fítico, não o utilizam por causa da baixa atividade ou ausência de atividade de fitase intestinal (Wodzinski \& Ullah, 1996). Tentativas de hidrólise enzimática do ácido fítico foram realizadas a fim de melhorar o valor nutricional dos alimentos e reduzir a quantidade de fósforo excretado pelos animais, diminuindo, assim, os problemas de poluição com fósforo em áreas de criação intensiva (Simons et al., 1990). Outros processos, como hidratação, moagem, maltagem, fermentação, tratamento térmico e germinação de sementes, também foram utilizados para redução do fitato (Reddy et al., 1982). Desta forma, a fim de melhorar a redução de fitato durante o processamento de alimentos, fitases exógenas poderiam ser adicionadas ou fitases endógenas poderiam ser ativadas. Greiner et al. (1998) descreveram que o isolamento e a caracterização de fitase, a partir de fontes microbianas ou vegetais, pode contribuir na obtenção de fitases efetivas com a finalidade de aplicação no processamento de alimentos.

Em muitos países, a produção e a utilização de girassol tem se expandido consideravelmente e no Brasil, há boas perspectivas para o seu crescimento. O girassol é uma oleaginosa de grande importância mundial, pela excelente qualidade do óleo comestível e aproveitamento dos subprodutos da extração do óleo para rações balanceadas (Rossi, 1997), ou na formulação de isolado protéico para enriquecimento de produtos de panificação e derivados cárneos (Reyes et al., 1985). Entretanto, produtos de girassol contêm também o ácido fítico, que pode prejudicar o seu uso na alimentação humana e animal.
O objetivo deste trabalho foi ativar, extrair e caracterizar parcialmente a fitase em sementes germinadas de girassol, e avaliar o efeito da fitase no farelo de girassol.

\section{Material e Métodos}

Foram utilizadas sementes de girassol (Helianthus annuus L.), híbrido M734, fornecidas pela Embrapa Soja e farelo de girassol desengordurado, fornecido por uma indústria de óleo de girassol.

As sementes de girassol foram hidratadas por cinco minutos em Tween 80 a 0,1\%, sanitizadas por dois minutos, em $\mathrm{NaOCl} 0,5 \%$, e mantidas por um minuto em $\mathrm{H}_{2} \mathrm{O}_{2} 0,75 \%$, de acordo com a técnica descrita por Konietzny et al. (1995). Depois da lavagem com água destilada e esterilização para remoção dos resíduos de sanitizantes, 50 sementes de girassol foram distribuídas sobre duas folhas de papel umedecido, próprio para germinação, cobertas com uma folha adicional, e mantidas enroladas por oito dias em câmara de germinação a $25^{\circ} \mathrm{C}$, com iluminação fluorescente externa. Depois de dois, quatro, cinco, seis e oito dias, as sementes germinadas foram liofilizadas e trituradas em moinho analítico, para análise do teor de fitato e atividade da fitase.

As determinações do teor de fitato e da atividade da fitase, do girassol germinado, foram feitas somente nos cotilédones. Essas determinações foram possíveis até o oitavo dia de germinação, pois a partir desse período o substrato de germinação utilizado não permitiu a continuação do desenvolvimento da planta.

A extração em triplicata de ácido fítico de farinha de sementes de girassol germinadas foi realizada com $2 \mathrm{~g}$ da farinha e $20 \mathrm{~mL}$ de $\mathrm{HCl} 0,8 \mathrm{M}$ na proporção sólido:líquido de 1:10 (peso/volume), e agitação a $250 \mathrm{rpm}$ por duas horas. O material foi centrifugado por dez minutos a $2.000 \mathrm{rpm}$ e o sobrenadante filtrado em papel-filtro. O teor de fitato foi quantificado segundo Latta \& Eskin (1980), com modificação da resina para Dowex-AGX-4, conforme descrição de Ellis \& Morris (1986). A leitura foi realizada em espectrofotômetro a $500 \mathrm{~nm}$ e os resultados foram expressos em gramas de fitato por 100 gramas de farinha de girassol, em base seca.

A extração e o fracionamento da fitase foram adaptados do método descrito por Lolas \& Markakis (1977). A solução bruta da enzima foi preparada a partir da farinha de sementes de girassol germinado do quinto dia, extração com $\mathrm{CaCl}_{2}$ 2\%, na proporção 1:10 (peso/volume) e agitação com refrigeração por uma 
hora. O material foi centrifugado a $20.000 \mathrm{~g}$, com refrigeração a $4^{\circ} \mathrm{C}$ por 30 minutos, e o resíduo descartado. $\mathrm{O}$ sobrenadante foi filtrado e adicionado lentamente o $\left(\mathrm{NH}_{4}\right)_{2} \mathrm{SO}_{4}$ até atingir $35 \%$ de saturação. A solução foi mantida em banho de gelo por 30 minutos e centrifugada novamente a $20.000 \mathrm{~g}$, com refrigeração a $4^{\circ} \mathrm{C}$ por 20 minutos. O resíduo foi descartado e o sobrenadante, ajustado a $80 \%$ de saturação com $\left(\mathrm{NH}_{4}\right)_{2} \mathrm{SO}_{4}$, também centrifugado como descrito. O precipitado obtido, contendo a fitase, foi solubilizado com $5 \mathrm{~mL}$ de tampão tris-maleato $0,01 \mathrm{M}, \mathrm{pH}$ 6,5, e dialisado por 48 horas no mesmo tampão a $2^{\circ} \mathrm{C}$. $\mathrm{O}$ material dialisado foi denominado de extrato bruto de fitase, e utilizado como fonte de fitase para caracterização parcial e hidrólise do fitato de farelo de girassol desengordurado.

A atividade de fitase foi determinada conforme Lolas \& Markakis (1977). Em tubo de ensaio contendo 0,2 mL de tampão acetato $0,6 \mathrm{M}, \mathrm{pH}$ 5,3, 0,15 mL de fitato de sódio $8 \mathrm{mM}$, pH 5,3, e 0,65 mL de água, foi adicionado $0,2 \mathrm{~mL}$ do extrato bruto de fitase. A incubação foi realizada em banho-maria a $50^{\circ} \mathrm{C}$ por 30 minutos. Depois da incubação, foi adicionado o ácido tricloroacético até concentração final de 0,7 M. Em seguida, a solução foi centrifugada e o fósforo inorgânico foi determinado no sobrenadante, de acordo com o método de molibdato de amônio modificado por Heinonen \& Lahti (1981). Uma unidade internacional de atividade de fitase (1 UI) foi definida como $\mu$ moles de fósforo inorgânico liberado por minuto nas condições de ensaio. O teor de proteínas solúveis do extrato bruto da enzima foi determinado pelo método de Lowry et al. (1951), e a atividade específica, definida pela relação entre a atividade da enzima e o teor de proteínas solúveis.

Na caracterização parcial da fitase do extrato bruto, foram investigados: o efeito do $\mathrm{pH}$ na atividade da fitase, utilizando os tampões acetato $0,1 \mathrm{M}(\mathrm{pH} 4,6-5,8)$ e tris-maleato, pH 6,0, com incubação a $55^{\circ} \mathrm{C}$ por 30 minutos; o efeito de temperatura de incubação de 35 a $70^{\circ} \mathrm{C}$, com intervalos de $5^{\circ} \mathrm{C}$, sobre as atividades da fitase em pH 5,2 por 30 minutos; a inativação térmica da fitase em tampão acetato $0,1 \mathrm{M}, \mathrm{pH}$ 5,2, com aquecimento por 10 minutos a temperaturas de 30 a $80^{\circ} \mathrm{C}$, com intervalos de 5 a $10^{\circ} \mathrm{C}$, sendo adicionado, depois do resfriamento, o fitato de sódio com concentração final de $1 \mathrm{mM}$, e determinada a atividade de fitase. O controle constituiu-se na determinação da ati- vidade de fitase, sem o pré-aquecimento, e foi considerado como $100 \%$ de atividade da enzima. Nessa caracterização, investigou-se também o efeito do período de incubação na atividade de fitase, utilizando $0,2 \mathrm{~mL}$ de tampão acetato $0,6 \mathrm{M}$ e pH 5,2, $0,15 \mathrm{~mL}$ de fitato de sódio $8 \mathrm{mM}, 0,65 \mathrm{~mL}$ de água destilada e $0,2 \mathrm{~mL}$ do extrato bruto de fitase, mantidos a $55^{\circ} \mathrm{C}$ e incubação de zero a 300 minutos, em intervalos iniciais de dez minutos e, depois, de uma em uma hora; o efeito da concentração do substrato na atividade de fitase, determinado em tempo de incubação de 30 minutos a $55^{\circ} \mathrm{C}$, em tampão acetato 0,6 M, pH 5,2 e com concentração de fitato de sódio de 0 a $10 \mathrm{mM}$. O $\mathrm{K}_{\mathrm{m}}$ e $\mathrm{V}_{\text {máx }}$ foram determinados pelo método de Lineweaver Burk (Nelson \& Cox, 2002).

O extrato bruto, contendo a fitase do girassol híbrido M734 germinado durante cinco dias, foi aplicado em farelo de girassol desengordurado para avaliar a atividade da enzima em um produto da indústria de óleo de girassol, utilizado na fabricação de ração. Em um frasco erlenmeyer de $250 \mathrm{~mL}$, contendo $2 \mathrm{~g}$ de farelo desengordurado de girassol, $20 \mathrm{~mL}$ de tampão acetato 0,6 M e pH 5,2 e $42 \mathrm{~mL}$ de água destilada, foram adicionados $8 \mathrm{~mL}$ da enzima bruta contendo $0,99 \mathrm{U} \mathrm{g}^{-1}$ de amostra e atividade específica de $0,10 \mathrm{U} \mathrm{mg}^{-1}$ de proteínas. A mistura foi agitada a $150 \mathrm{rpm}$ a $55^{\circ} \mathrm{C}$, e incubada de zero a oito horas. Depois de cada período de incubação, a mistura permaneceu em banho-maria fervente por dez minutos para inativar a enzima. Posteriormente, essa mistura foi transferida para placas de Petri e colocadas em estufa com circulação de ar a $40^{\circ} \mathrm{C}$ durante uma noite. Depois da secagem das amostras, foi determinado o teor de fitato.

\section{Resultados e Discussão}

Até oito dias de germinação, o fitato e as enzimas estavam presentes nos cotilédones ou primórdios foliares, ao passo que, nas partes axiais da plântula, o fitato e as enzimas não foram detectados pelos métodos utilizados.

Na Figura 1, é apresentado o perfil de atividade da fitase e o teor de fitato do girassol híbrido M734. Na germinação, houve uma reação típica de enzimasubstrato, com aumento característico da atividade de fitase e redução no teor de fitato. No segundo dia, o fitato decresceu 15,06\%; no quarto dia, reduziu 36,21\% e, até o oitavo dia, a redução foi gradual, atingindo 85,89\% em relação ao teor inicial. Eskin \& Wiebe 
(1983) observaram, em feijões, o decréscimo do fitato de 71 a 77\%, no décimo dia de germinação. Lu et al. (1987) relataram, em diversas variedades de canola, que o fitato diminuiu de 10 a 92\%, no oitavo dia de germinação, enquanto Houde et al. (1990) relataram decréscimo de $78 \%$ do fitato de canola da variedade Altex no oitavo dia de germinação. Beal \& Mehta (1985) observaram que houve redução do teor de fitato de até $75 \%$, no décimo dia de germinação, em ervilhas Garfield.

O perfil da atividade de fitase do girassol híbrido M734 foi típico em oito dias de germinação. A atividade da fitase em sementes não germinadas foi de $0,11 \mathrm{U} \mathrm{g}^{-1}$ de amostra. A atividade máxima da fitase ocorreu do quinto ao oitavo dia, com atividade de fitase mantida ao redor de $1,06 \mathrm{UI} \mathrm{g}^{-1}$ de amostra. Verificou-se aumento de 12 vezes na atividade de fitase no quinto dia do processo de germinação.

Houde et al. (1990) relataram atividade de fitase de 0,69 a 1,75 UI g$^{-1}$ de amostra, em diferentes variedades de sementes de canola, no oitavo dia de germinação. Konietzny et al. (1995) obtiveram máxima atividade de fitase (1,10 UI g ${ }^{-1}$ de amostra), no quinto dia de germinação de espelta. Greiner et al. (2000), ao estudar a atividade de fitase em cevada, descreveram que a atividade máxima de $1,35 \mathrm{UI} \mathrm{g}^{-1}$ de amostra, no quarto dia de germinação, foi quatro vezes maior em relação à da semente não germinada. Embora um aumento na atividade de fitase seja observado em sementes germinadas (Bartnik \& Szafranska, 1986; Eskin \& Wiebe, 1983; Lu et al., 1987), o mecanismo bioquímico não está totalmente esclarecido. É possível que o aumento de fitase em cereais possa ser atribuído à ativação de formas inativas de fitase (Greiner et al., 2000). Lolas \& Markakis (1977) descreveram que a fitase também

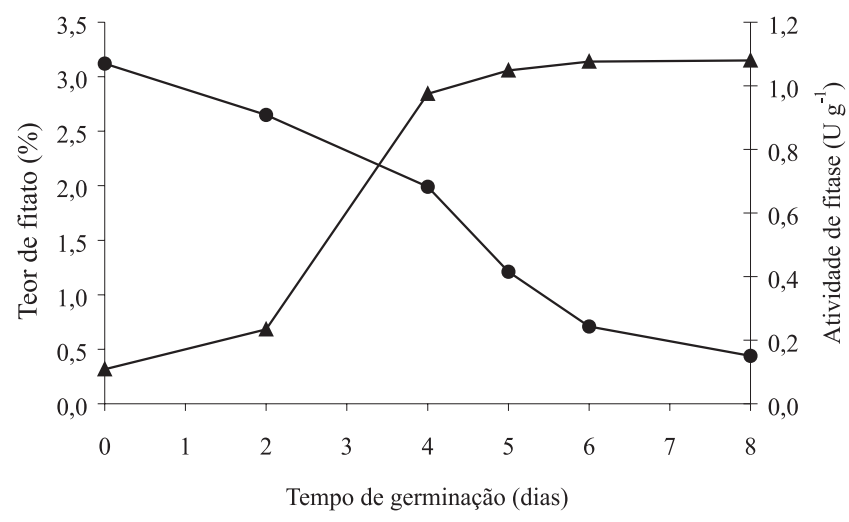

Teor de Fitato $\longrightarrow$ Atividade de Fitase

Figura 1. Atividade de fitase e teor de fitato de sementes de girassol híbrido M734, oito dias depois da germinação. hidrolisa o ácido fítico e outros fósforos-ésteres, assim como outras fosfatases também hidrolisam o fitato, embora não especificamente, durante a germinação de grãos. Conseqüentemente, o fitato não seria a única fonte de fosfato inorgânico proveniente da hidrólise pela fitase e fosfatases.

Na Figura 2, observa-se que a atividade de fitase foi máxima entre os valores de $\mathrm{pH}$ 5,0 e 5,4, com atividade máxima no pH 5,2. O pH ótimo de 5,2 é típico de fitases já descritas, em feijões-anões (Gibbins \& Norris, 1963), pequenos feijões-brancos (Chang et al., 1977) e canola (Houde et al., 1990). Em condições de incubação com $\mathrm{pH}$ a 4,6, observou-se a atividade da enzima entre 65 e $80 \%$ da atividade máxima, ao passo que em pH 6,0 a atividade foi mantida entre 40 e $60 \%$ da atividade máxima.

A máxima atividade de fitase em $\mathrm{pH}$ 5,2 foi observada entre as temperaturas de 50 e $60^{\circ} \mathrm{C}$, com atividade máxima a $55^{\circ} \mathrm{C}$ (Figura 3). Chang (1967) e Lolas \& Markakis (1977) observaram que a fitase de milho e feijões-navy apresentou maior atividade a $50^{\circ} \mathrm{C}$, enquanto Sutardi \& Buckle (1985) observaram que a fitase de soja apresentou atividade máxima a $60^{\circ} \mathrm{C}$. Peers (1953), Laboure et al. (1993) e Greiner et al. (2000) relataram que a fitase de trigo, milho e cevada apresentaram temperatura ótima de atividade a $55^{\circ} \mathrm{C}$.

A estabilidade térmica da fitase (Figura 4) do girassol híbrido M734 não foi afetada, quando as enzimas brutas foram pré-aquecidas a temperaturas de 30 a $50^{\circ} \mathrm{C}$, por dez minutos, e a atividade foi reduzida em cerca de $26 \%$, quando a enzima foi pré-aquecida a $60^{\circ} \mathrm{C}$ por dez minutos. Porém, foi observada perda de $90 \%$ da atividade, quando a enzima foi submetida a $80^{\circ} \mathrm{C}$ por dez minutos.

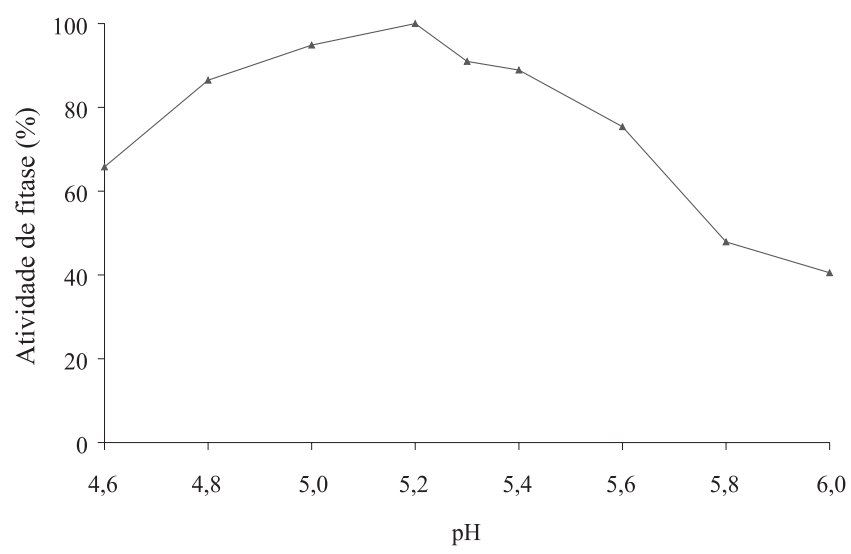

Figura 2. Efeito do $\mathrm{pH}$ na atividade de fitase de girassol híbrido M734, cinco dias depois da germinação. 
O perfil da estabilidade térmica de fitase de girassol (Figura 4) foi similar ao da fitase de milho (Chang et al., 1977), feijões-navy (Lolas \& Markakis, 1977) e soja (Sutardi \& Buckle, 1985); quanto à atividade da fitase no girassol, houve manutenção da estabilidade até $50^{\circ} \mathrm{C}$, redução gradual, de 50 a $80^{\circ} \mathrm{C}$, e inibição, em cerca de $90 \%$ da atividade, quando aquecida a $80^{\circ} \mathrm{C}$. Peers (1953) relatou que a atividade de fitase de farinha de trigo integral não alterou com o aquecimento a $80^{\circ} \mathrm{C}$ por 10 minutos, ao passo que, no extrato aquoso da mesma amostra, a atividade de fitase foi inibida depois do aquecimento a $70^{\circ} \mathrm{C}$ por dez minutos. Sutardi \& Buckle (1985) relataram que a resistência de atividade de fitase a tratamento térmico foi dependente da fonte da enzima.

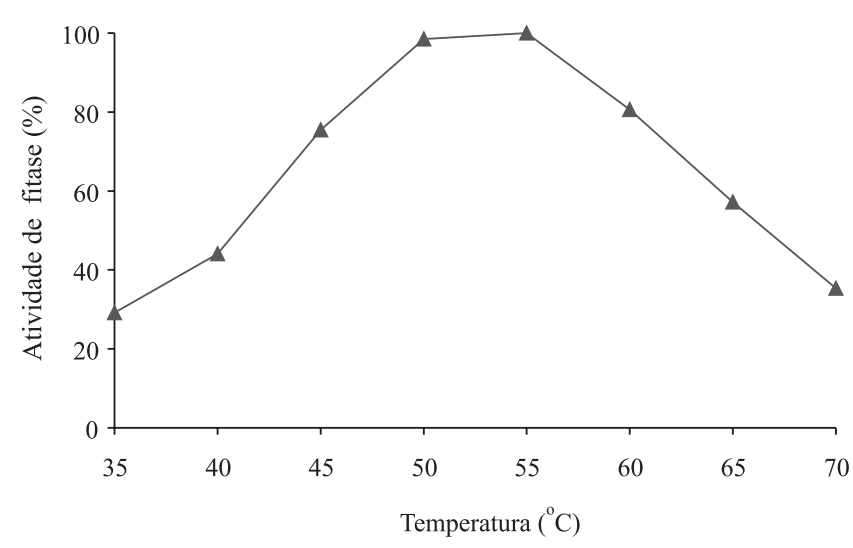

Figura 3. Efeito da temperatura na atividade da fitase de semente de girassol híbrido M734, cinco dias depois da germinação.

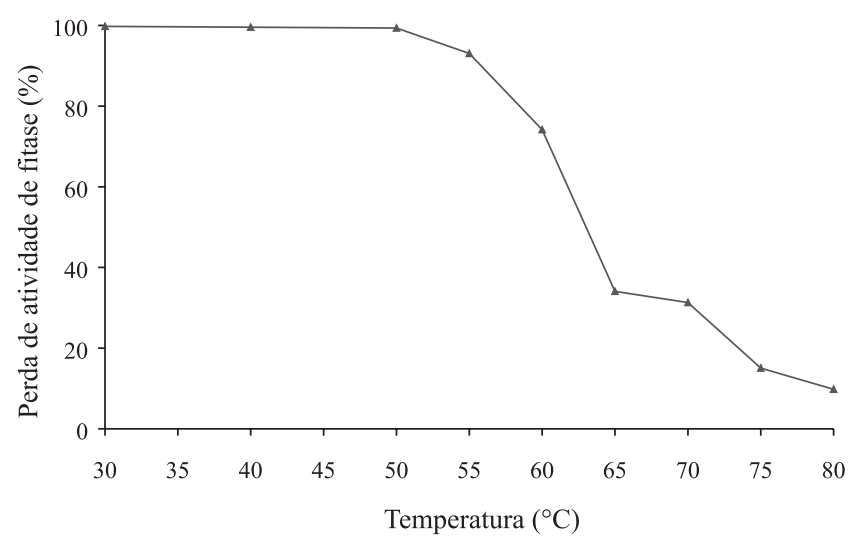

Figura 4. Perda de atividade da fitase de sementes de girassol híbrido M734, cinco dias depois da germinação.
A incubação aumentou gradualmente a atividade de fitase (Figura 5) por até duas horas a $55^{\circ} \mathrm{C}$, não sendo inibida pelos produtos de hidrólise. Depois da incubação por três horas, a atividade de fitase foi praticamente estável e indicou possível inibição de fitase pelos produtos finais, ou pela diminuição de substrato disponível para a reação. Sutardi \& Buckle (1985) observaram que a atividade de fitase da soja foi maior até uma hora de incubação e, depois desse período, a atividade da enzima diminuiu rapidamente, não sendo detectada depois de seis horas.

O gráfico da atividade de fitase em termos de $\mathrm{U} \mathrm{g}^{-1}$ de amostra foi plotado contra a concentração do substrato fitato (Figura 6). Observou-se que a atividade de fitase de girassol, com $1 \mathrm{mM}$ de fitato de sódio, qua-

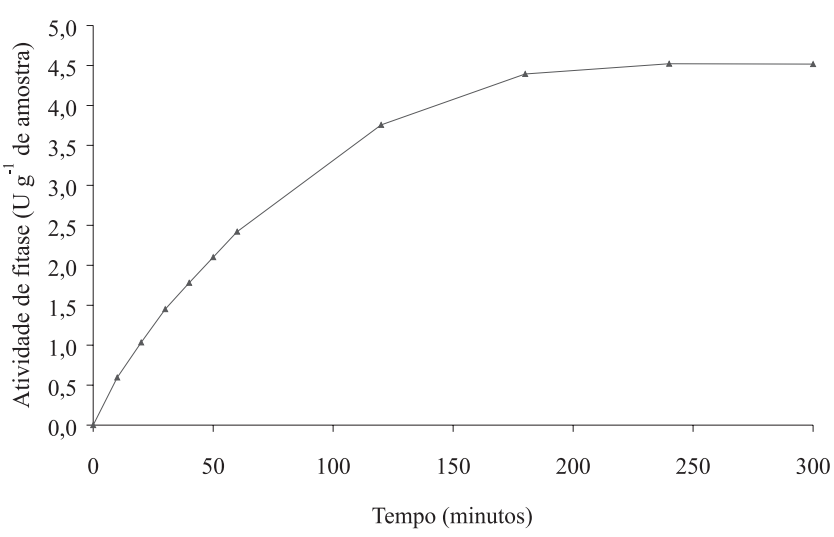

Figura 5. Efeito do tempo de incubação na atividade de fitase de sementes de girassol híbrido M734, cinco dias depois da germinação.

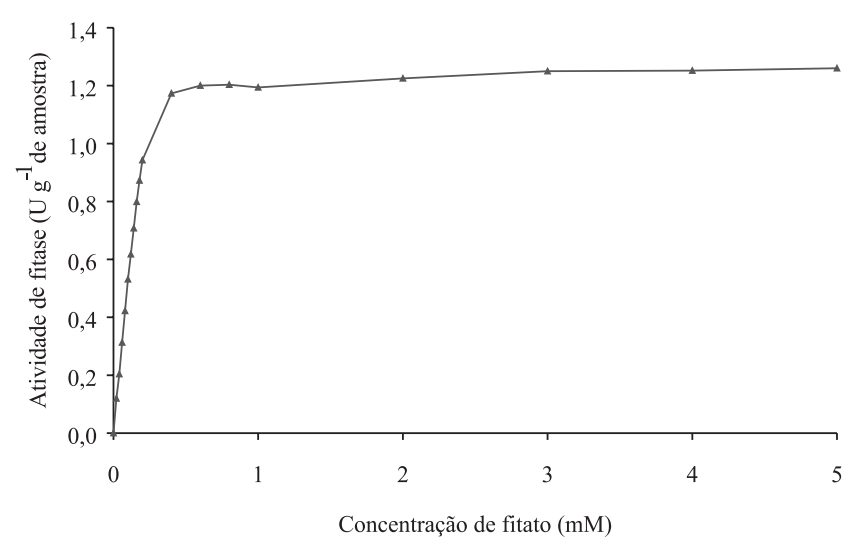

Figura 6. Efeito da concentração de substrato na atividade de fitase de sementes de girassol híbrido M734, cinco dias depois da germinação. 
se atingiu a máxima atividade e foi considerada como ótima para outros ensaios de caracterização da enzima.

A partir dos dados da Figura 6, foi possível traçar uma reta com os valores de $1 / \mathrm{v}_{0}$ versus os valores de $1 /[\mathrm{S}]$, cujo intercepto nas ordenadas é $1 / \mathrm{V}_{\text {máx }}$, e nas abscissas, $-1 / K_{m}$. Portanto, a partir da reta alocada de $1 / V_{0}$ versus 1/S (Nelson \& Cox, 2002), a velocidade máxima $\left(\mathrm{V}_{\operatorname{máx}}\right)$ e a constante de Michaelis $\left(\mathrm{K}_{\mathrm{m}}\right)$ foram encontradas, uma vez que a reta foi traçada a partir de pontos experimentais. Prolongando-se a reta até o eixo de ordenadas, encontrou-se o valor do inverso de $V_{\text {máx }}$ e o ponto em que a reta intercepta o eixo de abscissas forneceu o valor negativo do inverso de $\mathrm{K}_{\mathrm{m}}$. Portanto, o $\mathrm{K}_{\mathrm{m}}$ foi de $0,29 \mathrm{mM}$ e a $\mathrm{V}_{\text {máx }}$ foi de $1,87 \mu \mathrm{mol}$ de fósforo inorgânico liberado por minuto por grama de amostra. $\mathrm{O}$ valor resultante de $\mathrm{K}_{\mathrm{m}}$ de fitases do girassol híbrido M734 foi próximo ao da fitase de outros vegetais, tais como tremoço, que apresentou um $\mathrm{K}_{\mathrm{m}}$ de 0,33 mM (Silva \& Trugo, 1996), canola com $\mathrm{K}_{\mathrm{m}}$ de 0,36 mM (Houde et al., 1990) e trigo com $K_{m}$ de $0,30 \mathrm{mM}$ (Peers, 1953). Esses valores de $K_{m}$ indicaram alta especificidade da enzima pelo substrato.

Na incubação com farelo de girassol desengordurado (Figura 7), observou-se que o teor de fitato da amostra diminuiu em função do período de incubação. Cerca de $50 \%$ do fitato presente no farelo desengordurado de girassol foi degradado em três horas de incubação com as fitases, e $92 \%$ do fitato foram degradados em oito horas de incubação. Phillippy \& Wyatt (2001) observaram que, quando o extrato de fitases de folhas foi incubado com tortilhas de milho, aproximadamente $75 \%$ do fitato desses alimentos foram hidrolisados em 30 minutos, e, quando realizado com fitase endógena de abacate, cerca de $60 \%$ do fitato foi degradado em duas horas a $37^{\circ} \mathrm{C}$.

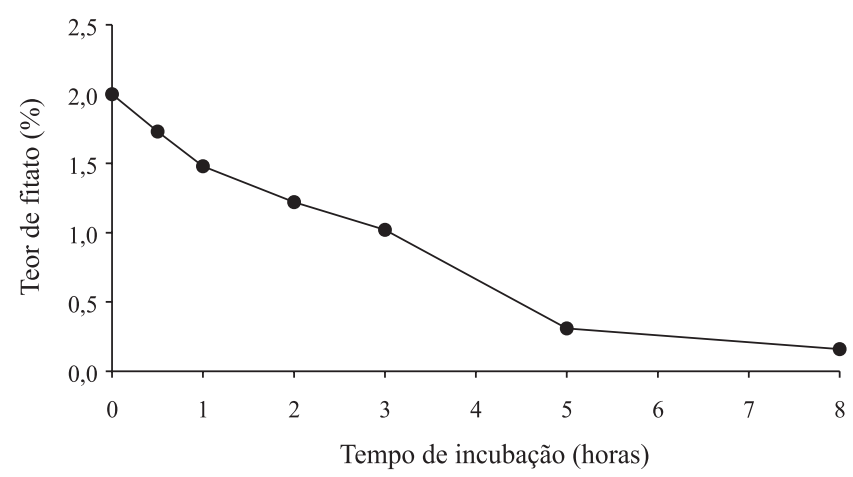

Figura 7. Efeito de fitase de sementes de girassol híbrido M734, cinco dias depois da germinação, na redução do teor de fitato de farelo de girassol desengordurado.

\section{Conclusões}

1. A máxima atividade de fitase ocorre entre o quinto e o oitavo dia de germinação da semente de girassol.

2. A fitase de sementes germinadas de girassol apresenta a máxima atividade a $55^{\circ} \mathrm{C}$ e $\mathrm{pH} 5,2$.

3. A fitase extraída de sementes germinadas de girassol é eficiente na redução do teor de fitato em farelo de girassol desengordurado.

\section{Agradecimentos}

Ao CNPq, pela concessão de bolsa; à Embrapa Soja, pelo fornecimento de girassóis híbridos.

\section{Referências}

BARTNIK, M.; SZAFRANSKA, I. Changes in phytate content and phytase activity during the germination of some cereals. Journal of Cereal Science, v.5, p.23-28, 1986.

BEAL, L.; MEHTA, T. Zinc and phytate distribution in peas. Influence of heat treatment, germination, $\mathrm{pH}$, substrate and phosphorus on pea phytate and phytase. Journal of Food Science, v.50, p.96-100, 1985.

CHANG, C.W. Study of phytase and fluoride effects in germinating corn seeds. Cereal Chemistry, v.44, p.129-142, 1967.

CHANG, R.; SCHWIMMER, S.; BURR, H.K. Phytate: removal from whole dry beans by enzymatic hydrolysis and diffusion. Journal of Food Science, v.42, p.1098-1101, 1977.

ELLIS, R.; MORRIS, E.R. Appropriate resin selection for rapid phytate analysis by ion-exchange chromatography. Cereal Chemistry, v.63, p.58-59, 1986.

ESKIN, N.A.M.; WIEBE, S. Changes in phytase activity and phytate during germination of two fababean cultivars. Journal of Food Science, v.48, p.270-271, 1983.

GIBBINS, L.N.; NORRIS, F.W. Phytase and acid phosphatase in the dwarf bean (Phaseolus vulgaris). Journal of Biochemistry, v.86, p.67-71, 1963.

GREINER, R.; JANY, K.D.; ALMINGER, M.L. Identification and properties of myo-inositol hexakisphosphate phosphohydrolases (phytases) from barley (Hordeum vulgare). Journal of Cereal Science, v.31, p.127-139, 2000.

GREINER, R.; KONIETZNY, U.; JANY, K.D. Purification and properties of a phytase from rye. Journal of Food Biochemistry, v.22, p.143-161, 1998.

HEINONEN, J.K.; LAHTI, R.J. A new and convenient colorimetric determination of inorganic orthophosphate and its application to the assay of inorganic pyrophosphatase. Analytical Biochemistry, v.113, p.313-317, 1981.

HOUDE, R.L.; ALLI, I.; KERMASHA, S. Purification and characterization of canola seed (Brassica sp.) phytase. Journal of Food Biochemistry, v.14, p.331-351, 1990. 
KONIETZNY, U.; GREINER, R.; JANY, K.D. Purification and characterization of a phytase from oat spelt. Journal of Food Biochemistry, v.18, p.165-183, 1995.

LABOURE, A.M.; GAGNON, J.; LESCURE, A.M. Purification and characterization of a phytase (myo-inositol-hexakisphosphate phosphohydrolase) accumulated in maize (Zea mays) seedlings during germination. Biochemical Journal, v.295, p.413-419, 1993.

LATTA, M.; ESKIN, M. A simple and rapid colorimetric method for phytate determination. Journal of Agricultural and Food Chemistry, v.28, p.1313-1315, 1980.

LOLAS, G.M.; MARKAKIS, P. The phytase of navy beans (Phaseolus vulgaris). Journal of Food Science, v.42, p.1094-1106, 1977.

LOWRY, O.H.; ROSEBROUGH, N.J.; FARR, A.L.; RANDALL, R.J. Protein measurement with the folin phenol reagent. Journal of Biological Chemistry, v.193, p.265-275, 1951.

LU, S.Y.; KIM, H.; ESKIN, N.A.M.; LATTA, M.; JOHNSON, S. Changes in phytase activity and phytate during the germination of six canola cultivars. Journal of Food Science, v.52, p.173-175, 1987.

MAGA, J.A. Phytate: its chemistry, occurrence, food interactions, nutritional significance, and methods of analysis. Journal of Agricultural and Food Chemistry, v.30, p.1-9, 1982.

NELSON, D.L.; COX, M.M. Lehninger: princípios de bioquímica. 3.ed. São Paulo: Sarvier, 2002. 975p.

PEERS, F.G. The phytase of wheat. Biochemical Journal, v.53, p.102-110, 1953.
PHILLIPPY, B.Q.; WYATT, C.J. Degradation of phytate in foods by phytases in fruit and vegetable extracts. Journal of Food Science, v.66, p.535-539, 2001.

REDDY, N.R.; SATHE, S.K.; SALUNKHE, D.K. Phytates in legumes and cereals. Advances in Food Research, v.28, p.1-92, 1982.

REYES, F.G.R.; GARIBAY, C.B.; UNGARO, C.B.; TOLEDO, M.C.F. Girassol: cultura e aspectos químicos, nutricionais e tecnológicos. Campinas: Fundação Cargil, 1985. 88p.

ROSSI, R.O. Girassol. Curitiba: Tecnoagro, 1997. 333p.

SEGUEILHA, L.; LAMBRECHTS, C.; BOZE, H.; MOULIN, G.; GALZY, P. Purification and properties of the phytase from Schwanniomyces castellii. Journal of Fermentation and Bioengineering, v.74, p.7-11, 1992.

SILVA, L.G.; TRUGO, L.C. Characterization of phytase activity in lupin seed. Journal of Food Biochemistry, v.20, p.329-340, 1996.

SIMONS, P.C.M.; VERSTEEGH, H.A.J.; JONGBLOED, A.W.; KEMME, P.A.; BOS, K.D.; WOLTERS, M.G.E.; BEUDEKER, R.F.; VERSCHOOR, G.J. Improvement of phosphorus availability by microbial phytase in broilers and pigs. British Journal of Nutrition, v.64, p.525-540, 1990.

SUTARDI; BUCKLE, K.A. Reduction in phytic acid levels in soybeans during tempeh production, storage and frying. Journal of Food Science, v.50, p.260-263, 1985.

WODZINSKI, R.J.; ULLAH, A.H.J. Phytase. Advances in Applied Microbiology, v.42, p.263-302, 1996.

Recebido em 17 de maio de 2005 e aprovado em 19 de janeiro de 2006 